\title{
Assessment of Knowledge and Practice of Adolescent In-School Girls Towards Menstrual Hygiene Management and Determining Factors in Lucy Village of Ethiopian Great Rift Valley, 2016
}

\author{
Bacha Kitesa, Tadesse Getahun, Kasim Wako \\ Department of Public Health, College of Medicine \& Health Science, Arsi University, Asella, Ethiopia
}

Email address:

bachakitesa@gmail.com (B. Kitesa),kitesab@yahoo.com (K. Wako)

To cite this article:

Bacha Kitesa, Tadesse Getahun, Kasim Wako. Assessment of Knowledge and Practice of Adolescent In-School Girls Towards Menstrual Hygiene Management and Determining Factors in Lucy village of Ethiopian Great Rift Valley, 2016. International Journal of Immunology. Vol. 4, No. 6, 2016, pp. 52-63. doi: 10.11648/j.iji.20160406.12

Received: October 18, 2016; Accepted: November 2, 2016; Published: December 17, 2016

\begin{abstract}
The issue of menstrual hygiene is inadequately acknowledged and has not received proper attention. Furthermore, It has not gained policy or program support. On the other hand, lack of adequate, safe and private sanitation facilities increase the suffering of pubescent school girls from health and psychosocial problems associated with the indignity experienced due to lack of a suitable place to change and dispose pads. Due to this, girls resort to use unhygienic practice or staying at home while on menstruation which affects their school attendance and performance rates. The main objective of this study was to assess knowledge and practice of adolescent school girls towards menstrual hygiene and its determining factors in Boset district, East shewa zone, Oromia regional state of Ethiopia. School based cross sectional study was employed and a multistage sampling technique was used to select 430 female high school students. Data collection was carried out from March 02-30, 2016 using pretested self administered questionnaire, Interview guideline and Focus group discussion (FGD). Data were entered, cleaned and analyzed using SPSS version 21.0. Finally Bivariate and multivariate logistic regression analysis was done at $95 \%$ confidence interval to assess independent effect of the predictors on the outcome variable. In this study, 305(70.9\%) and 302(70.2\%) have good knowledge and practice of menstrual hygiene, respectively. There is significant positive association between in school girls knowledge about menstruation and menstrual hygiene with their educational status $[(\mathrm{AOR})=1.5,95 \%(\mathrm{C} . \mathrm{I})=(3.7-6.8)]$ as well as with their mothers' and senior sisters' educational status $[\mathrm{AOR}=3.13,(95 \% \mathrm{CI})=1.32-7.37)]$. Nevertheless, educational status of the respondents $[\mathrm{AOR}=2.844$, $95 \% \mathrm{CI}=(1.355-5.97)]$ and access to WASH facilities $[\mathrm{AOR}=2.54,95 \% \mathrm{CI}=(1.355-5.97)]$ showed significant association with their practice toward menstrual hygiene. Majority of students have good knowledge and practice towards menstrual hygiene and its management. Similar result were discovered from the FGD and observation conducted in the study. Therefore, students need to be counseled on menstrual hygiene management. Further, gender inclusive water and toilet facility should be offered in the schools.
\end{abstract}

Keywords: Menstruation, Menstrual Hygiene, Knowledge, Practice, Sanitary Pads

\section{Introduction}

Early adolescence is a time of physical, intellectual, emotional, and social development during which young people exhibit physical and sexual maturation. This period refers to the onset of sexual maturation and it is the period under the influence of hormones when the child experiences physical and sexual changes and confront the questions like; self-concept and social relationship [1].

Around 3000 days of menstruation occurs in an average woman's lifetime which is an integral and normal part of women, indeed of human existence [2]. Menstruation is the cyclical shedding of the inner lining of the uterus and the endometrium under the control of hormones of the hypothalamic-pituitary axis. Menarche, or the onset of 
menstruation, is a landmark feature of female puberty and signals reproductive maturity [3].

Menstrual hygiene and management will directly contribute to MDG-2 on universal education, MDG-3 on gender equality and women empowerment [4]. However, the attention on this issue is far from sufficient and even the literature on gender mainstreaming in the sanitary section is silent on the issue of menstrual management [5].

The subject of menstruation is too often taboo and has many negative cultural attitudes associated with it; including the idea that menstruating women and girls are 'contaminated', 'dirty' and 'impure' [6]. For Example, In Egypt because of cultural and religious beliefs, menstruation is not considered an appropriate topic of discussion that lead to lack of accurate information for girls to manage their menstruation hygienically [7].

Women and girls in rural settings and in particular girls in schools suffer most from stigma and lack of services and facilities to help them cope with the physical and psychological pains they undergo during their menstrual periods. Some of the problems they face include inadequate preparations for young girls not yet experiencing menstrual hygiene; lack of or inadequate water to clean and wash the body, lack of materials for managing menstrual hygiene, no wash rooms and appropriate facilities for disposal of used pads. In spite of these issues, menstrual hygiene has been largely neglected by the WASH sector and other sectors focusing on sexual and reproductive health, and education [6].

Across sectional studies conducted in India revealed that only $36.95 \%$ of girls had awareness about menstruation before menarche and their main sources of information were mother $(71.33 \%)$ (8) while study done in west Ethiopia showed that $60.9 \%$ of the school girls had good knowledge about menstruation and its hygiene. However as far as my knowledge concerned there is no studies that have examined the KAP and its determining factors among in school girls towards MHM in Boset district. Therefore it is important to generate information for developing interventions that will be carried on problems associated with menstrual hygiene practice in the area.

According to the $2015 \mathrm{UNICEF/WHO} \mathrm{JMP,Access} \mathrm{to}$ basic facilities for menstrual hygiene management (MHM) is critically important for women's health, safety and dignity. Several essential elements are required, including clean materials to absorb or collect menstrual blood, a private place to change these materials as often as necessary, soap and water for washing body as required; and access to safe and convenient facilities to dispose of used materials. Further, women and girls need access to basic information about the menstrual cycle and how to manage it with dignity and without discomfort or fear [9].

Globally, there is very little comparable information available on menstrual hygiene management [9] and the issue of menstrual hygiene management is under estimated and has not received adequate attention in developing countries like Ethiopia [10].
Availability and quality of sanitation facilities including menstrual hygiene facilities will obviously influence the attendance of girls in school [8] while lack of privacy to change protective gear, the inability to have affordable sanitary napkins force the girls and women to use insanitary rag which is leading for the development of bad odor, RTI and skin problems. This creates young girls to be anxious restless and absent from school [11].

There is also a problem about menstrual hygiene management especially among communities those ignore talking about menstrual hygiene because talking about menstruation is taboo in their cultures [1] and many religion recognize a menstruating woman as impure. They have specific rituals and regulations on this group that restrict their movement and worship while on menstruation [12]

So this study assessed knowledge and practice of adolescent school girls towards menstrual hygiene management and determining factors in Boset district, East shoa zone, Oromia regional state, Ethiopia in 2016.

\section{Methods and Materials}

\subsection{Study Area}

The study was conducted in Boset woreda which is one of the districts found in eastern Shoa zone of Oromia regional state within the East Africa Great Rift Valley. It is $25 \mathrm{~km}$ from Adama and $125 \mathrm{~km}$ from Addis Ababa. According to the CSA 2010 the total population of this woreda is estimated around 142112 (Male: Female ratio; 52: 48) of which 52\% are males [25]. This district is located between $1400 \mathrm{~m}$ $2500 \mathrm{~m}$ above sea level that rest on 151406 hectare. On Average the district gets 600-900 millimeter annual rain fall and it was bounded in the north by Minjar district of Amhara regional state, by Fantale district in the east direction, by Marti district of Arsi zone in the south by Adama and Lume districts in the west [26].

The rainfall pattern of this district is erratic and it is characterized by rain shortage. The main economic activity of this woreda is agriculture. Maize, Teff, barley, sorghum and horticultural products are the main crops harvested in this woreda [26]

There are one Hospital, six health center (HC) and 31 heath posts providing health care services for residents of this woreda (HP)(26); while there are $351^{\text {st }}$ cycle primary school (grade 1 to 4 ), $372^{\text {nd }}$ cycle primary school (grade 5 to 8 ), 4 high school and 1 preparatory schools found in Boset district. A total of 38949 students (20041M and 18908F) are enrolled from grade 1 to 12 for the 2015/16 academic year in this district. Among this, a total of 2438 students $(1278 \mathrm{M}$ and $1160 \mathrm{~F}$ ) are enrolled from grade 9 to 12 for the $2015 / 16$ academic year.

\subsection{Study Design and Period}

School based descriptive cross sectional study was conducted from November-2015 to April-2016. 


\subsection{Source and Study Population}

All female students who were enrolled in secondary schools from 9 to 12 in Boset district in 2015/ 2016 academic year. The study population was all female adolescents sampled from grade 9 to 12 among the randomly selected schools during the 2015/ 2016 academic year.

\subsection{Eligibility Criteria}

A. Inclusion criteria: All female students from grade 9 to 12 enrolled for the regular program in Boset district in 2015/16 and those have no visual impairment and volunteer to participate in the study

B. Exclusion criteria: Those were seriously ill at the time of data collection, evening class students and visually impaired students were excluded.

\subsection{Sample Size Determination}

The sample size was determined based the assumption of simple random sampling (SRS) method using the formula for single population proportion and it was done by relying on the findings of the previous study conducted in West Ethiopia which found that the knowledge of adolescent school girls towards MHM which was $60.9 \%$ and the prevalence of girls using sanitary pads during menstruation which was $66.2 \%$ [19]. Finally, the prevalence of $60.9 \%$ was taken because it gave a larger sample size.

$$
\mathrm{n}=\mathrm{Z} 2 \partial / 2 \mathrm{p}(1-\mathrm{p}) / \mathrm{d} 2
$$

The sample size become 366 . However, since the source population was less than 10,000 finite population correction formulas

$$
\mathrm{nf}=\frac{\text { no }}{1+\mathrm{no} / \mathrm{N}} \text { was used. }
$$

Since multi-stage sampling method was implemented in this study, a design effects of 1.5 [1] was used to achieve the same precision as simple random sampling including a non response rate of $5 \%[1]$, the total final sample size reached 430.

\subsection{Sampling Procedure}

Multi stage sampling technique was implemented

\subsection{Data Collection Method and Materials}

Both qualitative and quantitative methods of data collection were implemented. Semi structured closed-end questionnaire, interview guide for key informant interviews, focus group discussion and checklist for observation were used to collected data from respondents.

\subsection{Data Quality Assurance and Analysis}

Moreover, data was coded, double entered, cleaned and analyzed using SPSS version 21.0. Moreover, bivariate analysis was performed between dependent variable and each of the independent variables one at a time. All variables found significant at bivariate level $(\mathrm{P}$-value $<0.05)$ were entered into Multivariate analysis using a logistic regression model to control for confounding factors. COR and AOR were considered at $95 \% \mathrm{CI}, 0.05$ level of significance.

\subsection{Study Variables}

\subsubsection{Dependent Variables}

Knowledge of students about menstrual hygiene management

Attitude towards menstrual hygiene management

Students practice towards menstrual hygiene management Determining factors of menstrual hygiene management

\subsubsection{Independent Variables}

Education status of respondents

Age of respondent

Place of residence

Religion

Source and preference of information on menstruation and related practices.

The occupation of families

Educational level of parents

Income of the family

Suitability of school environment for girls during menses Accessibility of sanitation facilities in school compounds Presence of sanitary pads

\subsection{Operational Definition}

Knowledge of menstrual hygiene management: Students menstrual knowledge score was calculated out of the 11 knowledge specific questions. Each correct response earned one point, whereas any wrong or don't know response attracted no mark and thus the sum score of knowledge was calculated (11 points). Respondents that scored 50\% and above were considered as having high level knowledge while a score of less than $50 \%$ as low level of knowledge as similarly described by previous study [1].

Menstrual Hygiene practice: Students practice of menstrual hygiene score was calculated out of the 6 practice specific questions. Each correct response earned one point, whereas any wrong or don't know response attracted no mark. In here, the sum score of practice was calculated (6 points). Respondents who scored $\geq 5$ were adjudge as having good practice while respondents who scored 0-4 points were adjudged as having poor practices as similarly described in previous study [19].

\subsection{Ethical Consideration}

Ethical Approval was obtained from Arsi University, College of health Sciences ethical clearance board and letter of collaboration was written to Boset woreda Education office. Approval letter was obtained from Boset Woreda Education Office and support letter was written for the respective schools

Data was collected after each study participant were adequately informed about the purpose, benefits and risks 
of the study and their right to discontinue or refuse to participate in the study. Permission to conduct the study was obtained from participating schools after school directors and directresses were briefed on the objectives of the study as well as written informed consent were obtained from the participants. For those students who were under the age of 18 years age of consent, informed verbal assent were obtained from their parents. Confidentiality of information was maintained by omitting any personal identifier from the questionnaires. The recorded data were stored in a safe place where no one except the principal investigators has access.

\section{Result}

\subsection{Distribution of Respondents by Socio-demographic Characteristics}

A total of 430 Study participants were involved with a response rate of $100 \%$. Out of the total respondents, $421(97.9 \%)$ of the respondents were in the age group 15-19 with median age of 16 years. $382(88.8 \%)$ of the respondents were single and 284(66\%) are from rural areas., 382(88.8\%) of the respondents were grade 9 students; the majority, $363(84.4 \%)$ were from the Oromo ethnic group and $166(38.6 \%)$ of them were Muslims, respectively, mean age at the first time of menarche is $13.69 \pm 1.183$ (Table 1).

Table 1. Respondents Socio-demographic characteristics in Boset distinct, East shoa Zone, and Oromia Regional state, Ethiopia, 2016.

\begin{tabular}{|c|c|c|c|}
\hline Variable & & Frequency $(n=430)$ & Percentage \\
\hline \multirow{4}{*}{ Age of respondents } & $<15$ & 7 & 1.6 \\
\hline & $15-19$ & 421 & 97.9 \\
\hline & $19-24$ & 2 & 0.5 \\
\hline & Singe & 382 & 88.8 \\
\hline \multirow[t]{2}{*}{ Marital Status } & Married & 18 & 4.2 \\
\hline & Engaged & 30 & 7 \\
\hline Educational Level & Grade 11 & 48 & 11.2 \\
\hline \multirow{5}{*}{ Ethnicity } & Oromo & 363 & 84.4 \\
\hline & Amhara & 50 & 11.6 \\
\hline & Gurage & 6 & 1.4 \\
\hline & Tigre & 8 & 1.9 \\
\hline & Other* & 3 & 0.7 \\
\hline \multirow{3}{*}{ Religion } & Orthodox & 138 & 32.1 \\
\hline & protestant & 111 & 25.8 \\
\hline & Waaqeffataa & 15 & 3.5 \\
\hline \multirow{2}{*}{ Residence of respondent } & rural & 284 & 66 \\
\hline & Urban & 146 & 34 \\
\hline
\end{tabular}

Table 2 below revealed that majority of the respondents' mothers 319(74.2\%) and fathers' 252(58.6\%) were illiterate while significant proportion $150(34.9 \%)$ of their senior sisters' were diploma and above. On the other hand, nearly two third, $290(67.4 \%)$ of the respondents' mother were housewives while $344(80 \%)$ of their fathers were farmers. Thus, $283(65.8 \%)$ of the respondent family gets monthly income less than 1000 Ethiopian Birr.

Table 2. Respondents Families' socio-demographic characteristics in Boset district, East Shoa zone, Oromia region, Ethiopia, 2016.

\begin{tabular}{|c|c|c|c|}
\hline Variables & & Frequency $(n=430)$ & Percentage \\
\hline \multirow{4}{*}{ Mother Educational Status } & Uneducated & 319 & 74.2 \\
\hline & Grade 1-6 & 11 & 2.6 \\
\hline & Grade $7-12$ & 73 & 17 \\
\hline & Diploma and above & 27 & 6.2 \\
\hline \multirow{4}{*}{ Educational status of Father } & Uneducated & 252 & 58.6 \\
\hline & Grade 1-6 & 24 & 5.6 \\
\hline & Grade $7-12$ & 86 & 20 \\
\hline & Diploma and above & 68 & 15.8 \\
\hline \multirow{4}{*}{$\begin{array}{l}\text { Educational status of senior } \\
\text { sister }\end{array}$} & Uneducated & 91 & 21.2 \\
\hline & Grade 1-6 & 71 & 16.5 \\
\hline & Grade $7-12$ & 118 & 27.4 \\
\hline & Diploma and above & 150 & 34.9 \\
\hline \multirow{4}{*}{ Occupation of mother } & House wife & 290 & 67.4 \\
\hline & Farmer & 80 & 18.6 \\
\hline & Government Employee & 9 & 2.1 \\
\hline & Daily Laborer & 18 & 4.3 \\
\hline
\end{tabular}




\begin{tabular}{llll}
\hline Variables & & Frequency $(\mathbf{n}=\mathbf{4 3 0})$ & Percentage \\
\hline \multirow{3}{*}{ Father Occupation } & Farmer & 344 & 80 \\
& Merchant & 24 & 5.6 \\
& Government Employee & 37 & 8.6 \\
& Daily Laborer & 20 & 4.7 \\
& Has no specific job & 5 & 1.2 \\
& $<100$ Birr & 61 & 14.2 \\
Monthly Family Income & 100-500 Birr & 96 & 22.3 \\
& 501-1000 Birr & 126 & 29.3 \\
& 1001-2500 Birr & 72 & 16.7 \\
\hline
\end{tabular}

\subsection{Knowledge About Menstruation and Its Hygiene Management}

From the total 430 respondents, majority of them $313(72.8 \%)$ heard of menstruation before. When asked about cause of menstruation, $302(70.2 \%)$ said menstruation is physiological process while $64(14.9 \%)$ mentioned it is a resulted from curse of God. Half of the respondents $215(50 \%)$ mentioned that the origin of the menstrual blood is from uterus while $144(33.5 \%)$ answer it is from vagina. Regarding cause of menstruation, $303(70.5 \%)$ of the respondents said it is hormonal action, $82(19.1 \%)$ curse from God, 24(5.6\%) disease and only $15(3.5 \%)$ mentioned as they do not know about cause of menstruation while 369(85.5\%) said there is a foul smell during menstruation and menstrual blood is unhygienic (Table 3 ).

Two hundred thirty eight $(55.3 \%)$ saw their first menstrual bleeding while at home followed by $87(20.2 \%)$ at school and $424(98.6 \%)$ of them had no expectation for their first day of menarche. Moreover, 111(25.8\%) of the respondents do not correctly remember their menstrual date schedule (Table 3 ).

$305(70.9 \%)$ of the respondents had good knowledge about menstruation and its hygienic management although there is a gap in specific areas, i.e. Only half, (50\%) of the respondents exactly responded as menstrual bleeding is from the uterus while $82(19.1 \%)$ of them said that curse of God is the major cause for menstruation.

Table 3. Respondents Over all Knowledge about menstruation and menstrual hygiene in Boset District, East shoa zone, Oromia region, Ethiopia. 2016.

\begin{tabular}{|c|c|c|c|}
\hline Variable & & Frequency & Percentage \\
\hline \multirow{2}{*}{ Heard about menstruation } & Yes & 313 & 72.8 \\
\hline & No & 117 & 27.8 \\
\hline \multirow{4}{*}{ Menstruation is } & Physiological process & 302 & 70.2 \\
\hline & Pathological process & 37 & 8.6 \\
\hline & Curse of God & 64 & 14.9 \\
\hline & I don't Know & 27 & 6.3 \\
\hline \multirow{3}{*}{ Source of menstrual bleeding } & Vagina & 144 & 33.5 \\
\hline & Blood vein & 56 & 13 \\
\hline & Abdomen & 15 & 3.5 \\
\hline \multirow{5}{*}{ Cause of menstruation } & Poverty & 6 & 1.4 \\
\hline & Curse Of God & 82 & 19.1 \\
\hline & Hormonal action & 303 & 70.5 \\
\hline & Disease & 24 & 5.6 \\
\hline & Don't Know & 15 & 3.5 \\
\hline Awareness about menstrual hygiene before attained it for the first time & No & 117 & 27.2 \\
\hline \multirow{2}{*}{ Knew that menstrual bleeding has foul smell } & Yes & 369 & 85.8 \\
\hline & No & 61 & 14.2 \\
\hline \multirow{2}{*}{ Knew that menstrual bleeding is un hygienic } & Yes & 371 & 86.3 \\
\hline & No & 59 & 13.7 \\
\hline \multirow{2}{*}{ Experienced menstruation before } & Yes & 430 & 100 \\
\hline & No & 0 & 0 \\
\hline \multirow{5}{*}{ Dou you remember place where you were when you seen your $1^{\text {st }}$ menarche } & At home & 238 & 55.3 \\
\hline & At school & 87 & 20.2 \\
\hline & At market place & 20 & 4.7 \\
\hline & At religious place & 36 & 8.4 \\
\hline & I don't remember & 49 & 11.4 \\
\hline \multirow{2}{*}{ Do you remember your menstrual date schedule } & Yes & 319 & 74.2 \\
\hline & No & 111 & 25.8 \\
\hline \multirow{2}{*}{ Do you know commercially made sanitary napkins products } & yes & 417 & 97 \\
\hline & No & 13 & 3 \\
\hline
\end{tabular}


As one could see from fig. 1 below, when respondents were asked about their source of information about menstruation and its hygienic management their leading source of information about menstruation were mother 157(36.5\%) followed by teacher 139(32.4.\%) (Fig. 1).

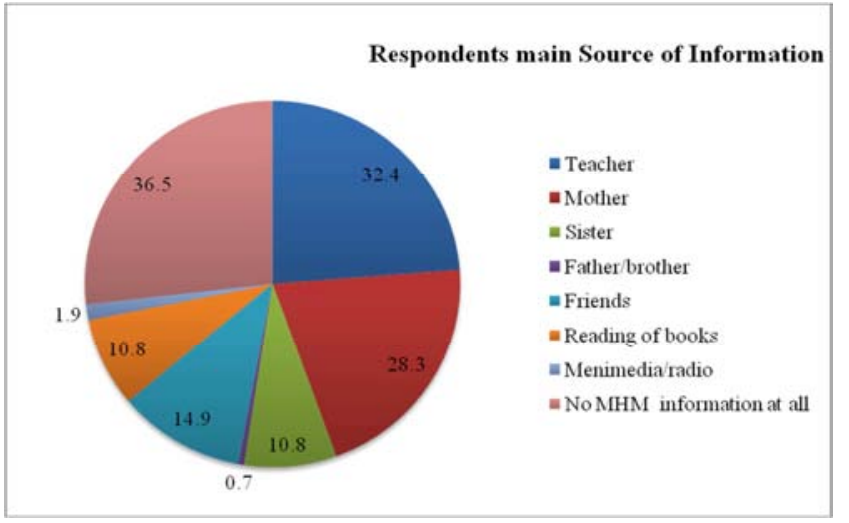

Figure 1. Respondents main source of information about menstruation and Menstrual hygiene in Boset district, East shoa, Oromia Region, Ethiopia 2016.

Table 4 below showed that, the association between respondents socio-demographic characteristic and overall knowledge about MHM. Accordingly, respondent's educational status, religion and area of their resident showed significant association with that of their knowledge about
MHM at $95 \% \mathrm{CI}$ and 0.05 level of significance.

Under multivariate analysis table 4 below revealed that grade eleven students were 1.5 times more likely know about menstruation and menstrual hygiene than their counter parts who were in grade nine $(\mathrm{AOR}=1.5,95 \%$ C.I (3.7-6.8), PV, 0.001]. On the other hand, students who were living in rural areas were 0.41 times less likely know about menstruation and menstrual hygiene than their counterparts $[\mathrm{AOR}=0.41$, 95\%C.I (0.22-0.76), PV, 0.004). Girls from mothers educated from grade 7-12 were 3.13 times more likely know about menstruation and menstrual hygiene than their counter parts whose were from uneducated mother $[\mathrm{AOR}=3.13,95 \% \mathrm{CI}$ (1.32-7.37), PV, 0.009). On the other hand, girls whose mothers educated diploma and above were 5.94 times more likely know about menstruation and menstrual hygiene that their counter $[\mathrm{AOR}=5.94,95 \% \mathrm{CI}(1.47-23.95), \mathrm{PV}, 0.012)$ (Table 4). In addition to this, educational status of senior sisters is also one of the predictors for girls knowledge about menstruation and menstrual hygiene under multivariate analysis. i.e. Girls who have sister educated from grade 1-6, $7-12$, diploma and above were respectively $2.96,6.9$ and 11.96 times more likely to know about menstruation and menstrual hygiene than their counterparts whose senior sisters' were uneducated [AOR $(95 \% \mathrm{C}$. I), PV: 2.96(1.356.75), 0.007, 6.9(3.32-14.4), 0.001) and 11.96(5.53-25.65), $0.001]$ (Table 4).

Table 4. Predictors of Knowledge about menstruation and menstrual hygiene among high school girls of Boset district, Oromia Region, Ethiopia, 2016 $(n=430)$.

\begin{tabular}{|c|c|c|c|c|c|c|c|}
\hline \multirow{2}{*}{ Characteristics } & & \multicolumn{2}{|l|}{ Knowledge } & \multirow{2}{*}{ COR $(95 \% \mathrm{CI})$} & \multirow{2}{*}{ P.val } & \multirow{2}{*}{ AOR $(95 \%$ CI) } & \multirow{2}{*}{ p.val } \\
\hline & & Poor $(\mathrm{N}, \%)$ & Good $(\mathrm{N}, \%)$ & & & & \\
\hline \multirow{2}{*}{$\begin{array}{l}\text { Educational status of } \\
\text { respondent }\end{array}$} & Grade 9 & $121(31.7)$ & $261(68.3)$ & 1 & & 1 & \\
\hline & Grade 11 & $4(8.3)$ & $44(93.7)$ & $5.1(1.8-14.5)^{*}$ & 0.00 & $1.5(3.7-6.8)^{* *}$ & 0.00 \\
\hline \multirow{4}{*}{ Religion } & Orthodox & $46(33.3)$ & $92(66.7)$ & 1 & & 1 & \\
\hline & Muslim & $52(30.7)$ & $115(69.3)$ & $1.13(0.67-1.82)$ & 0.63 & $0.98(0.53-1.84)$ & 0.9 \\
\hline & Protestant & 19(17.1) & $92(82.9)$ & $2.42\left((1.32-4.4)^{*}\right.$ & 0.00 & $2.1(0.97-4.54)$ & 0.06 \\
\hline & Waqefata & $9(60.0)$ & $6(40)$ & $0.3(0.11-0.93)^{*}$ & 0.05 & $0.88(0.01-0.41)^{*}$ & 0.00 \\
\hline \multirow{2}{*}{ Residence } & Urban & $24(16.4)$ & $122(83.6)$ & 1 & & 1 & \\
\hline & Rural & $101(35.6)$ & $183(64.4)$ & $0.36(0.22-0.6)^{*}$ & 0.00 & $0.41(0.2-0.76)^{*}$ & 0.00 \\
\hline \multirow{4}{*}{ Mother Educational status } & Uneducate & $107(34)$ & 208(66) & 1 & & 1 & \\
\hline & Grade 1-6 & $2(20)$ & $8(80)$ & $2.1(0.4-9.86)$ & 0.37 & $15.7(0.01-1.02)$ & 0.99 \\
\hline & Grade $7-12$ & $12(16.4)$ & $61(83.6)$ & $2.62(1.3-5.1)^{*}$ & 0.00 & $3.13(1.32-7.37)^{*}$ & 0.01 \\
\hline & $\geq$ Diploma & $4(12.5)$ & $28(87.5)$ & $3.6(1.2-10.5)^{*}$ & 0.02 & $5.9(1.47-23.9)^{*}$ & 0.01 \\
\hline \multirow{4}{*}{ Sister Educational status } & Uneducated & $54(59.3)$ & $37(40.7)$ & 1 & & 1 & \\
\hline & Grade 1-6 & $24(33.8)$ & $47(66.2)$ & $2.86(1.49-5.4)^{*}$ & 0.00 & $2.9(1.35-6.75)$ & 0.01 \\
\hline & Grade $7-12$ & $25(21.2)$ & $93(78.8)$ & $5.43(2.9-9.97)^{*}$ & 0.00 & $6.9(3.32-14.4)^{*}$ & 0.00 \\
\hline & $\geq$ Diploma & $22(14.7)$ & $128(85.3)$ & $8.49(4.59-15.7)^{*}$ & 0.00 & $11.9(5.53-25.6)^{*}$ & 0.00 \\
\hline
\end{tabular}

NB: Significant at $*$ P-value $<0.05,{ }^{* *} \mathrm{P}$-value $<0.01,{ }^{* * * P}$-value $<0.001$

\subsection{Practice Towards Menstruation and Menstrual Hygiene}

Table 5 below show that $302(70.2 \%)$ of the respondents have good practice towards menstrual hygiene management. From the total 430 respondents, 199(46.3\%) were use commercially made disposable sanitary pad though $35(8.1 \%)$ used rag (cloth of any kind). Half of the girls, 227(52.8\%) changed used pad only once per day whereas $142(33.0 \%)$ changed three times and above per day. $317(73.7 \%)$ of the respondents carry modus for emergencies. On the other hand, $281(65.3 \%)$ of the respondents throw used menstrual pads in 
the open field. Majority of the respondents, 292(67.9\%) wash their genitalia area with soap. however there is frequency gap taking bath or washing genitalia area. As a result, only
$243(56.5 \%)$ of the respondents take bath or wash their genitalia areas daily while $13(3 \%)$ do not take bath at all during menstrual episode (Table 5).

Table 5. Respondents hygienic practices during menstruation in Boset district, Oromia region, Ethiopia. 2016. (n=430).

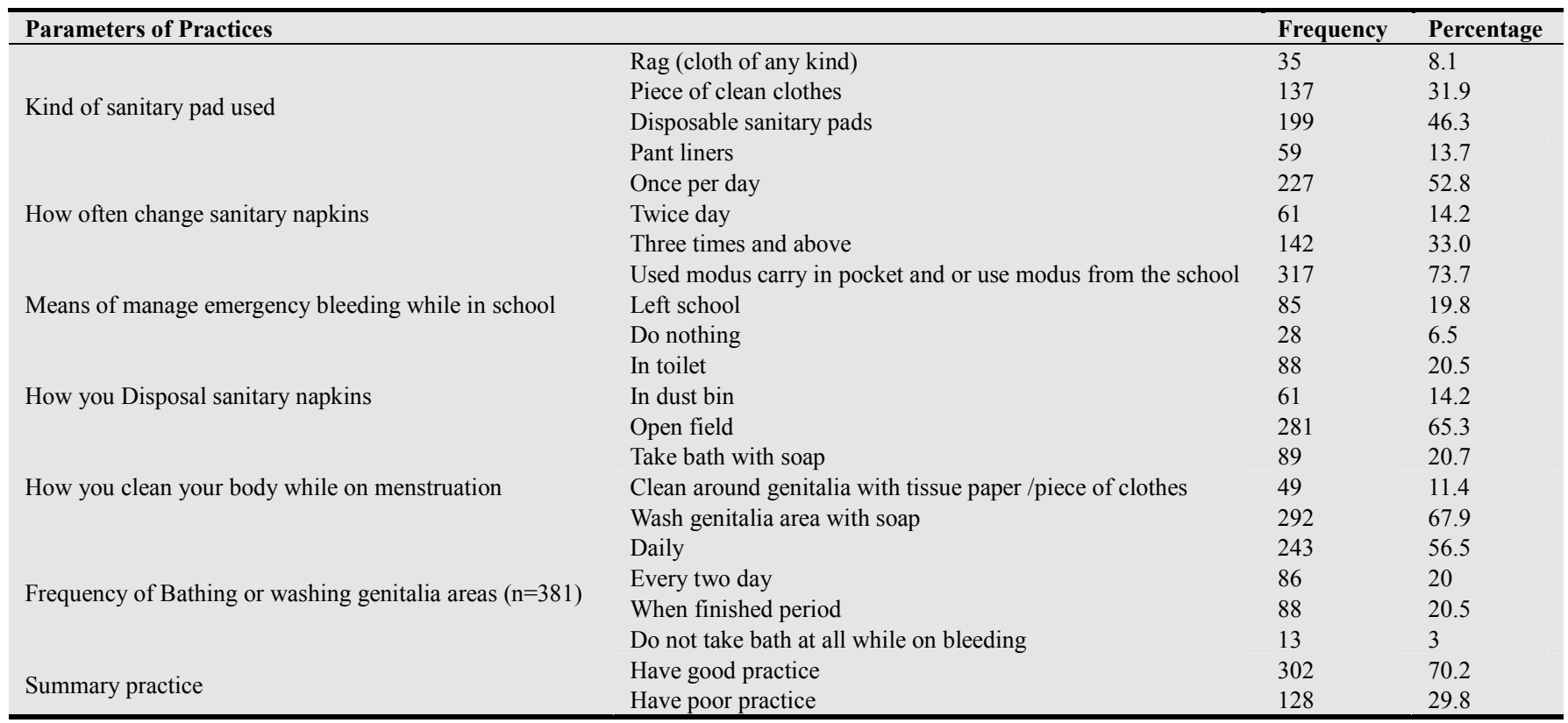

Table 6 below revealed that, educational status of the respondents and access to WASH facilities shows statistically significant association with students menstrual hygiene practice [AOR (95\% CI), PV: 2.84(1.35-5.97), 0.006] and [AOR (95\% CI), PV: 3.4(2.35-4.79), 0.002] respectively but religion, father and mother educational status as well as probability of getting pocket money for buying sanitary napkins were confounders (Table 6).
Students who were in grade 11 were 2.84 times more likely practiced good menstrual hygiene than their counterparts who were in grade nine $[(\mathrm{AOR}=2.84(1.35$ 5.97)]. While those accessed to WASH facilities (to water supply and clean and privacy secured toilet) were 3.4 times more likely practiced good menstrual hygiene management times than their counters who were not accessed $[\mathrm{AOR}=3.4$, 95\% CI=(2.35-4.79)] (Table 6)

Table 6. Predictors of practice towards menstrual hygiene management among high school girls in Boset district, Oromia Region, Ethiopia, 2016 ( $n=430)$.

\begin{tabular}{|c|c|c|c|c|c|c|c|}
\hline \multirow{2}{*}{ Characteristics } & & \multicolumn{2}{|l|}{ Practice } & \multirow{2}{*}{$\operatorname{COR}(95 \% \mathrm{CI})$} & \multirow{2}{*}{ p.val } & \multirow{2}{*}{$\operatorname{AOR}(95 \% \mathrm{CI})$} & \multirow{2}{*}{ P.val } \\
\hline & & Poor $(\%)$ & Good (\%) & & & & \\
\hline \multirow{2}{*}{ Educational status } & Grade 9 & $321(84)$ & $61(16)$ & 1 & & 1 & \\
\hline & Grade 11 & $28(58.3)$ & $20(41.7)$ & $3.76(1.2-7.1)$ & 0.001 & $2.84(1.35-5.97)$ & 0.006 \\
\hline \multirow{4}{*}{ Religion } & Orthodox & $101(73.2)$ & $37(26.8)$ & 1 & & 1 & \\
\hline & Muslim & $138(83.1)$ & $28(16.9)$ & $0.55(0.3-0.96)$ & 0.037 & $0.81(0.44-1.52)$ & 0.522 \\
\hline & protestant & 101(91) & $10(9)$ & $0.27(0.13-0.57)$ & 0.001 & $0.35(0.16-1.77)$ & 0.009 \\
\hline & waqefata & $9(60)$ & $6(40)$ & $1.82(0.6-5.46)$ & 0.286 & $1.33(0.4-4.4)$ & 0.637 \\
\hline \multirow{3}{*}{ Father Educational status } & Grade 1-6 & $21(87.5)$ & $3(12.5)$ & $0.89(0.25-3.14)$ & 0.856 & $0.62(0.13-2.82)$ & 0.532 \\
\hline & Grade $7-12$ & $59(68.6)$ & $27(31.4)$ & $2.85(1.6-5.08)$ & 0.001 & $1.65(0.86-3.16)$ & 0.133 \\
\hline & $\geq$ Diploma & $51(76.1$ & $16(23.9)$ & $1.95(1.0-3.8)$ & 0.048 & $1.14(0.52-2.54)$ & 0.739 \\
\hline \multirow{4}{*}{ Mother Educational status } & uneducated & $266(84.4)$ & $49(15,6)$ & 1 & & & \\
\hline & Grade 1-6 & $9(90)$ & $1(10)$ & $0.6(0.75-4.87)$ & 0.635 & $1.12(0.1-12.90$ & 0.927 \\
\hline & Grade $7-12$ & $50(68.5)$ & $23(31.5)$ & $2.49(1.4-4.4)$ & 0.002 & $1.8(0.94-3.46)$ & 0.076 \\
\hline & $\geq$ Diploma & $24(75)$ & $8(25)$ & $1.81(0.77-4.26)$ & 0.175 & $1.5(0.54-4.1)$ & 0.434 \\
\hline Money pocket & Yes & $165(76.4)$ & $51(23.6)$ & $1.9(1.15-3.12)$ & 0.012 & $1.5(0.87-2.59)$ & 0.142 \\
\hline \multirow{2}{*}{ Access to WASH Facilities } & No & $41(85.4)$ & $7(14.6)$ & 1 & & & \\
\hline & yes & $63(4.6)$ & $319(84)$ & $3.15(1.43-5.91)$ & 0.001 & $3.4(2.35-4.79)$ & 0.002 \\
\hline
\end{tabular}

NB: Significant at $* \mathrm{P}$-value $<0.05, * * \mathrm{P}$-value $<0.01, * * * \mathrm{P}$-value $<0.001$

As one can see from figure 2, majorities of, 309(71.9\%) of respondents said menstruation affected their academic performance or rank negatively as compared to what they had before their menarche. During menstruation days students didn't come to school or even if they came, they didn't attend class attentively thinking of the sudden leakage 
or the pain associated with menstruation. This was $153(31.4 \%)$ due to pain, 99(23\%) worried about having accidental leakage, 66(16\%) worried about other people might knew as she was on bleeding, while 44(10.2\%) and $20(4.7 \%)$ fear as other people might smell and feel sad respectively.

Figure 2. below show that, more than half 248(57.7\%) of the girls were absent from school during their menstrual period from one to seven days per month.

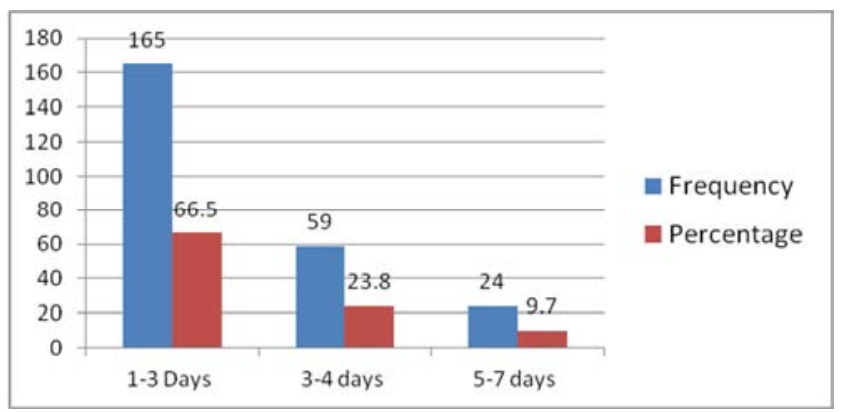

Figure 2. Number of days missed per month from class during menstrual period in Boset District, Oromia, Ethiopia, 2016.

\subsection{Result on Qualitative Study}

The qualitative study used checklist to make an inventory on the schools' facilities, an interview guide for key informants interview and focus group discussion and all the selected schools were visited. The FGD conducted revealed the presence of stigma toward menstruating women and associated as there was no ample and safe water in their school and all the latrines were dirty and not comfort privacy for girls to be used. In addition to this they also mentioned that latrines in their schools were generally small, poorly maintained, lacks proper waste disposal, hand washing and menstrual hygiene facilities which makes difficult for girls to change and dispose of absorbent materials discreetly (Figure 3). On the other hand, even though there were water connection in the three schools they did not give service due to continues cut-off water while there was no water connection at all in Bole high school and this school got water by bought from water vendors found in their town (Figure 3).

"Common terms used express menstruation and menstruating women are 'xurii, laguu, dugda and misirroo in Oromiffa and war-ababa and Keye shash Aserech in Amharic'..... FGD participant from girls club"

"There is bad attitude towards menstruating women. Especially male students teased at if saw menstruating girls.... FGD participant school Director ".

“... I had never had a bath while having my periods, as people often say, it might aggravate the bleeding"...(FGD participants)...."I had never gone religious places while on my periods, as I learnt from my spiritual, God might curse If I might did it so.....FGD participants among girls from Bole high school "

"...My Families did not allowed for me to attend my school even they did not allow me to walk on the road when I am on bleeding from the fear that if person having sprit (kalicha) come to me the sprit will be disturbed and fall down the person on the ground and will curses me as I never give birth in the future....FGD participant girl from Doni high school."

".. Girls on menstruating couldn't walk on the road when there is religious ceremony. It was not allowed for women to shake hands of spiritual fathers (kalicha, priests and sheiks) when on menstrual bleeding from the fear that God may curse as she will never give birth.....FGD participant PTA."

"Girls were ashamed if they saw bleeding while in class and they stayed on their seat until all students left the class.....Girl club head FGD participant Bole high school."

"I Am not comfortable to use the latrine where men and boys are around and I find it difficult to dispose the used sanitary pads...due to this I left at home while I am on bleeding and returned home to defecate....FGD participant from Bole high school."

The FDG conduced with School WASH and girl clubs also revealed as students have been negatively impacted for the lack of MHM intervention in their schools. The Participants added lack of WASH facilities in schools negatively impacted girl student's educational attendance which further impacted their educational performance.

... No water, no washing room, no safe resting room, no napkins for emergency menstrual bleeding. For that reason, I have no option rather than left at home during my period... FDG participant girls from Bole High school

"... My attention to education or class is decreased during my menstruation and I didn't concentrate my attention in the class. I disturbed by the thinking of the sudden leakage of menstrual blood and staining of the cloth... FDG participants from Boset High school”

\section{Discussion}

According to this study, the mean age of the respondents at the first time of menarche was $13.69 \pm 1.183$. This is consistent with the findings of the study conducted among Addis Ababa school girls [15].

In this study, 305(70.9\%) of the respondents had good knowledge about menstruation and menstrual hygiene. The finding is higher than the result of the study done in west Ethiopia which showed that only $60.9 \%$ had good knowledge about menstruation and menstrual hygiene [19]. This difference might be due to girls got correct information about menstruation and menstrual hygiene from teachers who were their main source of information.

Majority of the girls, 313(72.8\%) heard about menstruation before its onset and teachers were the main source of information about menstruation for the students $(32.8 \%)$, followed by their mother $(28.25 \%)$. This result is consistent with the finding conducted in Egypt where 74\% of the participants had been informed about menarche before its onset and mother was the first person informed about menarche to her daughter $(70.5 \%)$, followed by friends (14.1\%) and elder sisters (10.1\%) [18]. 
According to the multivariate analysis of this study, students who were living in rural areas were 0.41 times less likely know about menstruation and menstrual hygiene than their counterparts Girls from mothers educated from grade 712 were 3.13 times more likely to know about menstruation and menstrual hygiene than their counterparts. On the other hand, girls whose mothers had diploma and above were 5.94 times more likely know This study agreed with the study conducted in Amhara regional state in Ethiopia that place of residence $(\mathrm{AOR}=1.8,95 \% \mathrm{CI}:[1.42-1.52])$ and mother educational status $[(\mathrm{AOR}=95 \%$ CI: 1.15-13.95)] were independent predictors of knowledge about menstrual hygiene management [10]. The reason could be that educated mothers may provide information about menstruation and menstrual hygiene to their daughters. Girls from educated families may discuss openly about sexual and reproductive health issues including menstruation.

This study further discover that students who attended grade eleven were 1.5 times more likely know about menstruation and menstrual hygiene than their counter parts. In addition to this, girls knowledge about menstruation and menstrual hygiene were improve with educational status of their senior sister. i.e. Girls who have sister educated from 1$6,7-12$, diploma and above were respectively 2.96, 6.9 and 11.96 times more likely to know about menstruation and menstrual hygiene than their counterparts whose senior sisters' were uneducated This finding is different from the study done in Amhara regional state which didn't show significant relation between knowledge about menstrual hygiene with respondents educational status and as well as with their senior sister educational status [10]. This might be due to the fact that girls learn more about menstruation and its hygienic management as they advance in their school (For example according to the Ethiopian educational curriculum students started to learn about topic of menstruation started from grade six for the first time).

Only $199(46.3 \%)$ of the respondents use commercially made sanitary pads. This is lower than the findings of the study done in west Ethiopia (19). On the other hand half of the girls changed used pad once per day and 281(65.3\%) of the respondents throw used pads on open field. This indicate that menstrual hygiene practice is at embryonic stage in the study area when compared with the study done in Mehalmeda where $34.8 \%$ of girls changed pads at least twice a day while $51.4 \%$ of them throw used menstrual pads in the toilet pan [1]. This difference might be due to the knowledge gaps on menstrual hygiene management, lack of access to wash facilities and menstrual napkins.

From the total four hundred thirty girls participated on this study $70.2 \%$ have good practice of menstrual hygiene management. This is lower than the finding of the study conducted in Amhara regional state among Mehalmeda students were $90.9 \%$ of the students had good practice [1]. This difference might be due to the fact that Mehalmeda students had more accessed to WASH facilities (water supply and sanitation facilities) and get accurate menstrual hygiene management information, from their teachers, who are their primary source of information about menstrual hygiene management.

According to the findings of cross sectional studies conducted in Amhara $70.9 \%$ of study participants use commercially made sanitary pad [1]. On the other hand according to the study conducted in west Ethiopia, $66.2 \%$ of girls use commercially made sanitary pads during menstruation [20]. These results were greater than the current study in which only $46.3 \%$ of the respondents used commercially made sanitary pad while $35(8.1 \%)$ used rag (cloth of any kind). This difference could be due to students in the current study areas were not accessed to commercially mad sanitary pads or couldn't afford it.

According to the finding of this study, Educational status of the respondents and access to WASH facilities were predictors of the students menstrual hygiene management. Students who were in grade 11 were 2.84 times more likely practiced good menstrual hygiene than their counterparts who were in grade nine while those accessed to WASH facilities were 3.4 times more likely practiced good menstrual hygiene management times than their counters who were not accessed. This was parallel to the finding of the study conducted in Amhara regional state which found that students who have access for water were more practiced good menstrual hygiene than those who didn't have access for water [1].

Menstrual hygiene practice have significant association with place of residence [1] and with probability of getting pocket money [19]. But the finding of this study did not support this fact., This could be due to girls who live in urban areas may get more information about menstrual hygiene, accessed to the sanitary napkins and students those got pocket money may afforded easily

More than half, of girls were absent from school during their menstrual period from one to seven days per month. According to the cross sectional study conducted in north west Ethiopia $43 \%-50.7 \%$ of students were absent from school due to menstruation related problems, ranging from one day to four days [16]. This difference might be due to lack of WASH facilities (lack of ample and clean water supply, lack of clean and privacy maintained toilet and lack of napkins changing rooms for girls.

The qualitative data also supported this finding as there were misconceptions and adverse attitudes towards menstruation. Furthermore, all the schools lack MHM inclusive sanitation facilities (including sanitary napkins, private place to change napkins and ample water supply).

\section{Strength and Limitation of the Study}

\subsection{Strength}

(1) Data was collected from primary sources

(2) Mixed data collection method was employed 100 percent response rate

(3) Data collectors had exposure before this time and were well experienced for exit interview 
(4) Qualified data collectors used for observation of client/provider interaction

\subsection{Limitations}

(1) Due to its cross-sectional nature of the study, it is difficult to establish causal relationship between the dependent and predicting variables.

(2) Basically, the study addressed the sensitive issue about menstrual hygiene and the possibility of social desirability bias is unavoidable even if I have tried my best to minimize it.

(3) It is difficult to acquire the exact age of menarche as there may be recall bias and also girls do not report their exact age as there is no birth registration in Ethiopia and girls might tend to underestimate their age.

\section{Conclusion}

According to the study finding, most (70.9\%) of the respondents showed good knowledge about menstruation and menstrual hygiene. Indeed, the findings showed a significant positive association between knowledge about menstruation and menstrual hygiene management with educational status of girls, mothers and senior sisters as well as with their place of residence.

Most adolescent school girls have good practice of menstrual hygiene management whereas, educational status of the respondents and access to WASH facilities (to ample and clean water supply and to clean and privacy maintained latrine) were revealed significant association with good practice of menstrual hygiene.

Consequently, More than half, $57.7 \%$ of girls were absent from their class from 1 to 7 days per month during their menstrual period from the factors associated with their knowledge, attitude and practice towards menstruation and menstrual hygiene. This is mainly from lack of disposable sanitary napkins and sanitation facilities at schools (accessibility and affordability to WASH facilities and sanitary napkins).

\section{Recommendation}

According to the finding of this study, the investigators in debated to forward the following recommendations:

- The government should give special emphasis on making the accessibility of water and toilet facility in the school which decreases school absenteeism of female students due to menstrual hygiene problem.

- It is very important that the families should have the correct and appropriate information on menstrual hygiene and to break the silence around menstruation

- The schools should have conduct awareness creation through its girl and WASH club on menstruation and menstrual hygiene.

- Researchers has to do large scale study on menstrual hygiene by employing both qualitative and quantitative methods
- policy makers and stakeholders should setup health education program to create awareness and practice of good menstrual hygiene

\section{Acknowledgement}

Above all, I thank my God for all his kindness in my life. Next, I would like to express my gratitude and special thanks to Dr. Tadesse Getahun and Kasim Wako for their valuable support in advising this study starting from the initial stage to the end. I also thank Arsi university, college of health sciences, department of public health for giving me this opportunity. I also acknowledge staffs of Boset Woreda Education Office, Bole and Doni high school and Boset preparatory, and all the supervisors and data collectors for their active participation and cooperation on the study. Finally, my sincere acknowledgement goes to my wife Nimona Tolina for her kind support during the course of my study.

\section{Annex-Pictures}

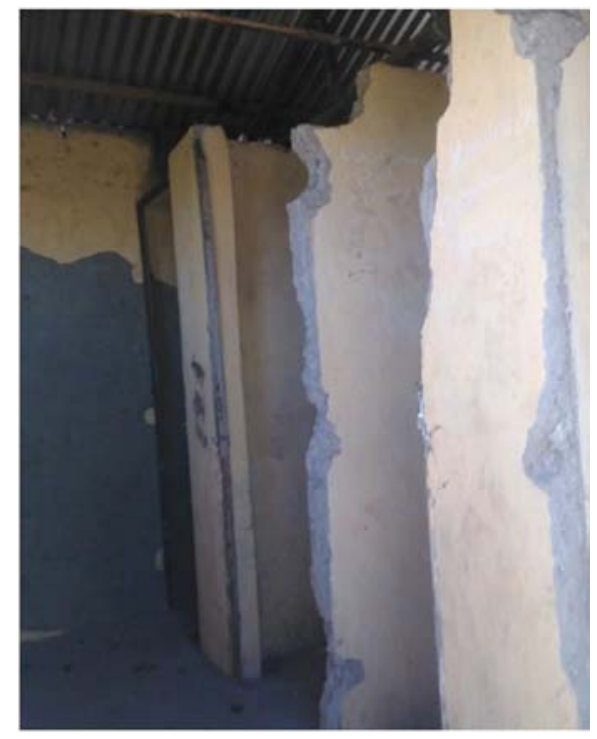

Figure 3. Latrine did not maintain privacy, all the doors to sitting rooms were broken and inside of the sitting rooms were full of feces.

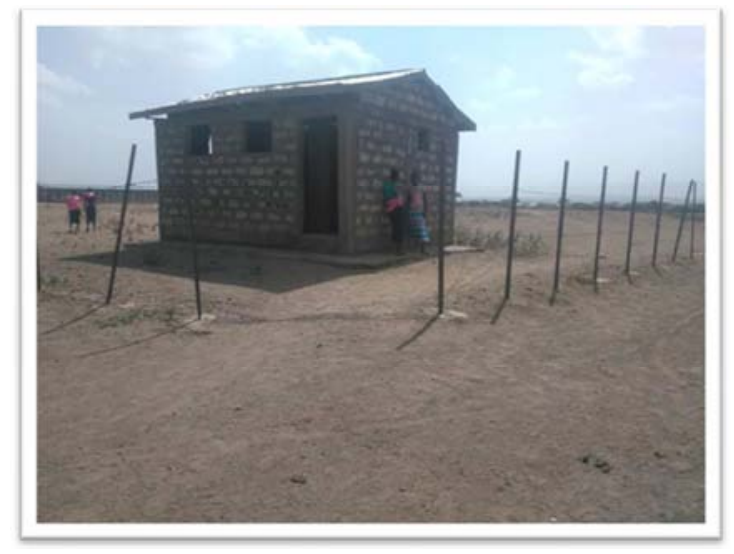

Figure 4. Girls toilet open for passengers due to the broken of school fences in Doni Elementary school, Boset district, East shoa, Oromia Ethiopia, 2016. 


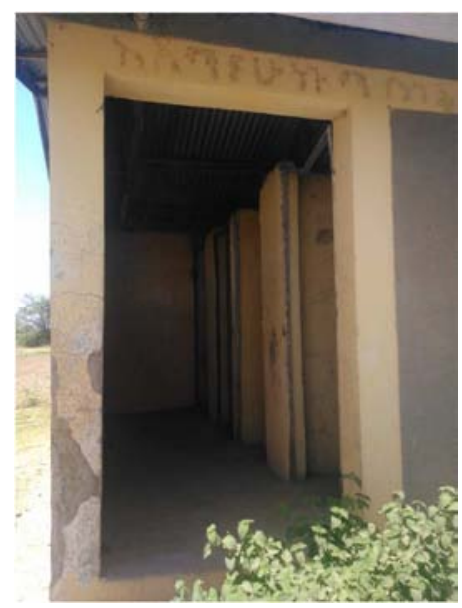

Figure 5. Broken latrine under use by girls in Doni Secondary school in Boset district, Oromia region, Ethiopia. 2016.
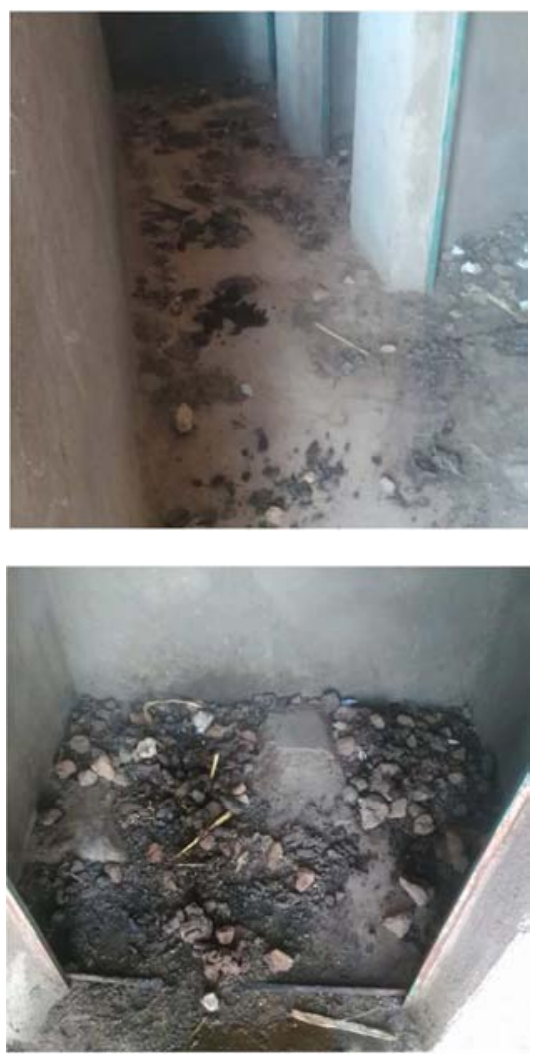

Figure 6. VIP Latrine for girls in Bole High school during of data collection in Boset District, Oromia, Ethiopia. 2016.

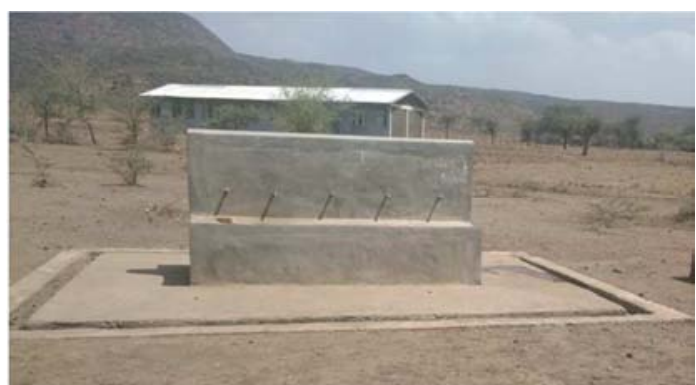

Figure 7. Water supply scheme in Doni High school; the school did not get water due to frequent water cut during data collection; Boset district, Oromia region, Ethiopia. 2016.

\section{References}

[1] Gultie T. Practice of menstrual hygiene and associated factors among female Mehalmeda high school students in Amhara regional state, Ethiopia. Science Journal of Public Health. 2014; Vol. 2(3): 189-95.

[2] Patkar MHM girls in control project facts; Preparatory Input on Menustrial hygiene managment MHM for End Group, WSSCC. 2014

[3] T A. Menstrual Hygiene: A neglected condition for the achievement of the Millennium Development Goals. Europe External policy Advisors. 2007.

[4] Water aid, Is Menstrual Hygiene and Management an issue for Adolescent Girls?'. Water Aid in South Asia Publication. 2009.

[5] Netherlands SNV) NDO. Main report on menstrual management IRC International Water and Sanitation Centre 2012: 23 .

[6] El-Gilany A BK, El-Fedawy S. Menstrual hygiene among adolescent schoolgirls in Mansoura, Egypt. Reproductive Health Matters. 2005; 13: 147-52.

[7] Thakr DS. Knowledge andPractice among Adolescent School Girlsof Saoner, Nagpur District. Journal of Clinical and Diagnostic Research. 2011; volme 5(5): 1027-33.

[8] WHO/UNICEF. MDG assessment on Progress of sanitation and drinking water.. Joint Monitoring Programme (JMP. 2015: 44.

[9] Gultie T HD, Workineh Y. Age of Menarche and Knowledge about Menstrual Hygiene Management among Adolescent School Girls in Amhara Province, Ethiopia: Implication to Health Care Workers \& School Teachers. 2014.

[10] Menstrual Hygiene Must Become a Matter of Public Concern in Zimbabwe. [database on the Internet]. global mother hood one story, one world 2015 [cited November 11, 2015].

[11] Belayhun B. WASH Knowledge, Attitude \& Practices (KAP) Survey, Analysis and Communication Strategy Report on (Eight Towns and 27 Satellite Villages). UNICEF. 2015.

[12] Nation S-U. THE 2030 AGENDA FOR SUSTAINABLE DEVELOPMENT UN geneal assembly summit for the adoption of the post-2015 development. New yorrk: UN; 2015. p. 15-9.

[13] Shabnam Omidvar KB. Factors influencing hygienic practices during menses among girls from south India- A cross sectional study. International Journal of Collaborative Research on Internal Medicine \& Public Health. December 2010; Vol. 2 No. 12: pp. 411-23.

[14] Abera Y. Menarche, Menstruation related Problems and Practices among Adolescent High School Girls in Addis Ababa,: Addis Ababa University; 2003/04.

[15] Annabel S AF, Worku A, etal. Ethiopia Young Adult Survey: A Study in Seven Regions. Addis Ababa, Ethiopia. Population Council. 2010.

[16] Zinash Tsegaye ST, Adane Kitaba, et al. towards alocal solution to menustrial hygiene SNV Netherlands Development Organisation. 2011. 
[17] Abeer Eswi HH, and Wafaa Elarousy. Menstrual Attitude and Knowledge among Egyptian Female Adolescents Journal of American Science,. 2012; 8(6): 555-65.

[18] al Ue. Assessment of knowledge and practice of menstrual hygiene among high school girls in Western Ethiopia. BMC Women's Health. 2015.

[19] Obuya H. First National Menstrual Hygiene Management Conference. In: NETWAS, editor.; Uganda - Biina Luzira 2014.

[20] UNESCO. Good Ploicy and Practice in Health Education 'Puberty Education and Menustrial Hygiene Management' Paris: UNISCO; 2014.

[21] Sommer M, Emily Vasquez, Nancy Worthington and Murat Sahin, WASH in Schools Empowers Girls' Education: Proceedings of the Menstrual Hygiene Management in
Schools Virtual Conference 2012. United Nations Children's Fund and Columbia University 2013.

[22] Menstrual Hygiene Practices and Reproductive Morbidity. A community based survey in rural Thiruvanantha Apuram, Kerala [database on the Internet]. Public Health. 2003.

[23] Madian RBE-LaAAE-A. Impact of Health Educational Program on Menstrual Beliefs and Practices of Adolescent Egyptian Girls at Secondary Technical Nursing School. Life Science Journal. 2013; 10: 2.

[24] Boset District Education office oE. Education Office 2015 annual report. In: Education, editor. Boset-Ethiopa 2015.

[25] Gutu T BK, Zekariyas A and Kebede D. Urban water, sanitation and hygiene vulnerability assessment in selected towns of Ethiopia. World Vision Ethiopia and BINAT consultancy. 2015: Addis Ababa, Ethiopia. 